\title{
Transition Metal (Fe, Co, Ni) Nanoparticles on Selective Amino-N-Doped Carbon as High-Performance Oxygen Reduction Reaction Electrocatalyst
}

\author{
Seonghee Kim ${ }^{1}$, Shuhei Kato ${ }^{2}$, Takahiro Ishizaki ${ }^{2} \mathbb{( D}$, Oi Lun Li ${ }^{1, * \mathbb{C}}$ and Jun Kang ${ }^{3, *(1)}$ \\ 1 School of Materials Science and Engineering, Pusan National University, Busan 46241, Korea; \\ ksh08280@naver.com \\ 2 Department of Materials Science and Engineering, College of Engineering, Shibaura Institute of Technology, \\ Tokyo 135-8548, Japan; mb18008@shibaura-it.ac.jp (S.K.); ishizaki@shibaura-it.ac.jp (T.I.) \\ 3 Division of Marine Engineering, Korea Maritime and Ocean University, Busan 606-791, Korea \\ * Correspondence: helenali@pusan.ac.kr (O.L.L.); junkang@kmou.ac.kr (J.K.)
}

Received: 27 March 2019; Accepted: 9 May 2019; Published: 14 May 2019

\begin{abstract}
Metal-air batteries are attracting increasing attention as a superior renewable energy conversion device due to their high performance and strong potential. However, the high cost and low stability of the current Pt catalyst is the main obstacle preventing wide industrial application. In this work, we applied a plasma process to fabricate aniline and a transition metals electrode $(\mathrm{Fe}, \mathrm{Co}, \mathrm{Ni})$ as the carbon-nitrogen and the metal nanoparticle (NP) precursors, respectively, for selective metal/amino-N-doped carbon catalysts. All three as-synthesized catalysts exhibited dominant amino- $\mathrm{N}$ as the major $\mathrm{C}-\mathrm{N}$ bonding state. In electrochemical testing, $\mathrm{Co} / \mathrm{amino}-\mathrm{N}$-doped carbon showed positive $\boldsymbol{E}_{1 / 2}$ potential ( $0.83 \mathrm{~V}$ vs. Reversible Hydrogen Electrode (RHE)). In addition, the calculated electron transfer number $(n)$ of $\mathrm{Co} / \mathrm{amino}-\mathrm{N}$-doped carbon at $0.5 \mathrm{~V}$ vs. RHE was 3.81 , which was only slightly less than that of commercial Pt/C (3.97). This superior performance of transition metal/amino- $\mathrm{N}$-doped carbon promotes it as an economical oxygen reduction reaction (ORR) electrocatalyst to replace expensive $\mathrm{Pt} / \mathrm{C}$ in metal-air batteries.
\end{abstract}

Keywords: nitrogen-doped carbon; transitional metal nanoparticles; oxygen reduction reaction; metal-nitrogen-hybrid catalyst; selective amino-N doping

\section{Introduction}

Within the accelerating application of renewable energy in many fields, metal-air batteries have been spotlighted as one of the candidates for a next-generation energy conversion device, mainly due to their high theoretical energy density, simple structure, and variety of component designs [1-4]. When air is used as the cathode fuel, the oxygen reduction reaction (ORR) that occurs at the cathode governs the performance of the overall system. However, due to the difficulties of $\mathrm{O}_{2}$ chemical sorption/activation, the slow reaction rate of ORR often limits the system performance [4,5]. To date, platinum (Pt) shows the best performance as an ORR catalyst and has often been applied in practical metal-air batteries. Commercial Pt catalysts are composed of $20 \mathrm{wt}$ \% Pt nanoparticles (NPs) on a high-surface-area carbon support. Nevertheless, the high capital cost and scarcity of Pt have prompted researchers to develop other alternatives to replace $\mathrm{Pt} / \mathrm{C}[6]$.

Recently, nitrogen-doped carbon (N-doped carbon), which is a sub-group of the heteroatom-doped carbon catalysts, has attracted much attention due to its high catalytic performance and superior stability [7-13]. The catalyst often shows relatively high catalytic performance in alkaline electrolytes. In the case of N-doped carbon, nitrogen reduces the charge density of the nearby carbon atoms due to the differences in electronegativity of carbon and nitrogen. As a result, the nitrogen dopant can induce 
charge delocalization, which not only polarizes carbon to a positive charge to promote adsorption of the $\mathrm{O}_{2}$ molecule but also promotes ORR by changing the chemisorption mode of $\mathrm{O}_{2}$ from end-on adsorption (Pauling model) to side-on adsorption (Yeager model) $[7,14,15]$. Many studies suggest that total $\mathrm{N}$ content does not contribute significantly to improving ORR, whereas the bonding state of the $\mathrm{N}$ atom does [16]. The improvement in ORR activity has been attributed to pyridinic- $\mathrm{N}$ and graphitic-N by many studies [17-20]. Also, selective doping of graphitic-N and pyridinic-N can be easily controlled by heat treatment due to their high thermal stability, and different $\mathrm{C}-\mathrm{N}$ bonding states affect the different performances of ORR, such as the selective electron pathway $\left(4 \mathrm{e}^{-}\right.$or $\left.2 \mathrm{e}^{-}\right)$, current density and onset potential [17]. By using this concept, the performance can be improved by tuning towards dominant pyridinic-N bonding or by controlling the ratio of pyridinic-N/pyrrolic-N for the selective $2 \mathrm{e}^{-}$pathway in industrial $\mathrm{H}_{2} \mathrm{O}_{2}$ synthesis [21,22]. Compared to metal-free $\mathrm{N}$-doped carbon catalysts, the doping of transition metals such as $\mathrm{Fe}, \mathrm{Ni}$, and $\mathrm{Co}$ on $\mathrm{N}$-doped carbon support further enhanced the ORR catalytic activities. Many studies proposed that the metal dopant (especially $\mathrm{Fe}, \mathrm{Co}$ ) on $\mathrm{N}$-doped carbon coordinated by nitrogen groups, such as pyridinic- $\mathrm{N}$ or metal-N moieties $\left(\mathrm{FeN}_{2}\right.$, $\mathrm{FeN}_{4}, \mathrm{CoN}_{4}, \mathrm{CoN}_{2}$ ), enhances the ORR activity [23-30]. For instance, Kramm et al. reported Fe-N moieties $\left(\mathrm{FeN}_{4}\right)$ can improve ORR activity significantly without the presence of inorganic metal nanoparticles [27]. Peng et al. reported a high catalytic performance of Fe-N-doped carbon with dominant graphitic-N and pyridinic-N in both alkaline and acidic electrolytes [29]. Du et al. fabricated various types of transition metal $(\mathrm{Fe}, \mathrm{Ni}, \mathrm{Co})$ catalyst on $\mathrm{N}$-doped carbon, and reported that $\mathrm{Fe}-\mathrm{N}$-doped carbon showed the highest potential of $0.96 \mathrm{~V}$ [30]. Other researches also showed that not only $\mathrm{M}-\mathrm{N}_{\mathrm{x}}$ moieties, but also metal nanoparticles (NPs) can improve ORR performance. Peng et al. reported superior ORR onset potential for $\mathrm{Fe}$ and $\mathrm{Co}$ on $\mathrm{N}$-doped carbon derived from polyaniline and melamine, and suggested that the transition metals (Fe and $\mathrm{Co}$ ) provided a synergic effect between the metal NPs and N-doped carbon matrix [31]. Tang et al. synthesized porous nitrogen-doped graphitic carbon fibers embedded with metal and metal oxide particles. In particular, $\mathrm{Co}, \mathrm{Co}_{3} \mathrm{O}_{4}$ with $\mathrm{N}$-doped carbon support exhibited comparable ORR performance to $\mathrm{Pt} / \mathrm{C}$ in alkaline media with high stability and strong methanol tolerance [32]. Zeng et al. reported Fe-N-doped carbon composed with FeN particles covered by graphitic carbon layers with a high specific surface area. The as-synthesized catalysts showed superior ORR performance, including high ORR onset potential and low peroxide yield rate, which were both comparable to that of $\mathrm{Pt} / \mathrm{C}$ [33].

A few studies also suggested that amino-N could enhance ORR activity, especially in the onset potential of reaction. Due to the electron donating effect of an amine group, amino-N works as an electron donating group in $\mathrm{N}$-doped carbon and improves the electron conductivity of carbon support [34-36]. However, amino- $\mathrm{N}$ has the lowest thermal instability $\left(<550{ }^{\circ} \mathrm{C}\right)$ among all $\mathrm{C}-\mathrm{N}$ chemical bonds [34]. Thus, it is very challenging to dope amino-N selectively by conventional high-temperature chemical vapor deposition or post-annealing treatment. Zhang et al. first fabricated selective amino-N-doped carbon catalysts by the hydrothermal method at a moderate temperature of $200{ }^{\circ} \mathrm{C}$. Their study showed that amino-N enhances ORR activity with a more positive onset potential [34]. Li et al. applied a room-temperature plasma process to synthesize selective amino-N and pyridinic-N by varying the liquid precursors. The ORR onset potential was enhanced with a higher ratio of amino-N [36]. To date, the synergic effect of transition metals on amino-N-doped carbon has yet to be reported.

As the plasma process is a room-temperature bottom-up method, it is beneficial for maintaining the molecular structure, in particular, amino-N with the lowest thermal stability among all types of $\mathrm{C}-\mathrm{N}$ bonding. In addition, transition metal NPs can be generated simultaneously by electrode sputtering during plasma discharge [37-44]. In this study, we applied the same process to fabricate transition metal ( $\mathrm{Fe}, \mathrm{Ni}$ or $\mathrm{Co}$ ) NPs on selective amino-N-doped carbon catalysts. Aniline was chosen as a precursor for dominant amino-N bonding, while the pure metal electrodes were the precursor of $\mathrm{Fe}$, Co or Ni NPs. The physical and chemical properties of three electrocatalysts were firstly characterized, 
and their corresponding electrochemical performance was evaluated in detail and compared to that of commercial 20 wt.\% Pt/C.

\section{Materials and Methods}

\subsection{Synthesis of Metal (Fe, Co, Ni)-N/C Catalyst by A Plasma Process}

The plasma was discharged between a pair of high purity transition metal (Fe, Co, Ni) electrodes (99.999\%, Nilaco Co., Ltd., Tokyo, Japan, diameter of $1 \mathrm{~mm}$ ) inside a pure aniline solution (purity $>99 \%$, Junsei Chemical Co., Ltd., Tokyo, Japan) by using a bipolar pulse power supply (MPP-HV02, kurita Seisakusho, Kyoto, Japan). The plasma was discharged at a voltage of $\sim 4 \mathrm{kV}$, a frequency of $50 \mathrm{kHz}$, and a pulse width of $1.0 \mu$ s (Figure 1a). A stable plasma was discharged for $30 \mathrm{~min}$ to obtain $1 \mathrm{~g}$ samples. The solution was filtered using a $\Phi 55 \mathrm{~mm}$ polytetrafluoroethylene filter, and the resulting filtered carbon powder samples were dried in an oven for $10 \mathrm{~h}$ at $80^{\circ} \mathrm{C}$. Finally, the samples were heated to $800{ }^{\circ} \mathrm{C}$ for $1 \mathrm{~h}$ under nitrogen gas in order to improve their electrical conductivity. We hereafter named the as-synthesized samples as Fe-N/C, Co-N/C, and Ni-N/C. The schematical structure of N-doped carbon support is shown in Figure 1b.
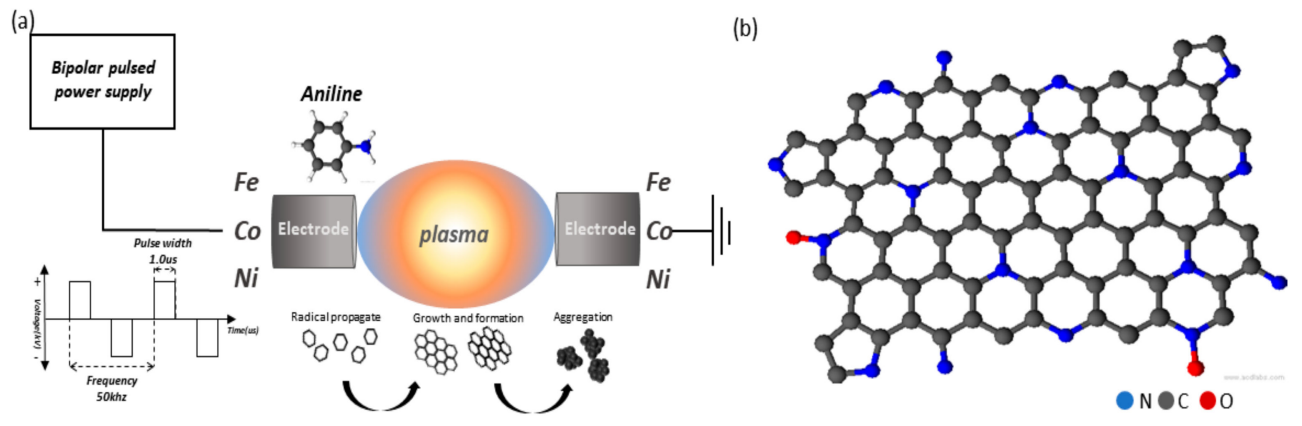

Figure 1. (a) Schematic illustration of the solution plasma process and synthesis of metal (Fe, $\mathrm{Co}$, $\mathrm{Ni})-\mathrm{N} / \mathrm{C}$ catalyst, and (b) structure of N-doped carbon catalyst.

\subsection{Structure and Chemical Composition Analysis}

The nitrogen absorption-desorption method (BET, Brunauer Emmett Teller; TriStar-II3020, Shimadzu, Tokyo, Japan,) was used for analyzing the surface area, pore volume and pore diameter of the synthesized metal-N/C powder. For morphology and chemical composition analysis, the samples were characterized by scanning electron microscopy (SEM; JEOL, JSM-7100F, Tokyo, Japan), X-ray diffraction (XRD; Rigaku, Ultima IV, Tokyo, Japan) and X-ray photoelectron spectroscopy (XPS; JEOL, JPS-9010MC, Tokyo, Kanto, Japan).

\subsection{Electrochemical Measurements}

An electrochemical analyzer (Biologic, VSP, Grenoble, France) was used to analyze the electrochemical properties of the synthesized $\mathrm{N}$-doped carbon samples. The catalyst ink for the electrochemical analysis was made by adding $5 \mathrm{mg}$ of well ground metal (Fe, Ni, Co)-N/C catalyst into a mixture composed of $280 \mu \mathrm{L}$ of distilled water, $200 \mu \mathrm{L}$ of ethanol and $20 \mu \mathrm{L}$ of Nafion®117 Solution, which was then ultrasonicated for $30 \mathrm{~min}$. A total of $5 \mu \mathrm{L}$ of well-dispersed catalyst ink was applied onto a well-polished GC disk (diameter: $3 \mathrm{~mm}$ ) electrode (working electrode), where a platinum coil and $\mathrm{Ag} / \mathrm{AgCl}$ (saturated $\mathrm{KCl}$ ) were used as the counter and reference electrodes, respectively. After the three-electrode cell was prepared, cyclic voltammetry $(\mathrm{CV})$ was measured in $\mathrm{O}_{2}$ saturated $0.1 \mathrm{M} \mathrm{KOH}$ with a scan rate of $50 \mathrm{mVs}^{-1}$ and a potential range of $-1.0 \mathrm{~V}$ to $0.4 \mathrm{~V}$. Linear sweep voltammetry (LSV) was conducted in $\mathrm{O}_{2}$ saturated $0.1 \mathrm{M} \mathrm{KOH}$ with a scan rate of $10 \mathrm{mVs}^{-1}$ and rotating speed of $1600 \mathrm{rpm}$, between a potential range of 0 to $1.2 \mathrm{~V}$ vs. RHE. 


\section{Results}

\subsection{Properties of Metal (Fe, Ni, Co)-N/C Catalyst}

The SEM images reveal the morphology of metal (Co, Fe, Ni)-N/C in Figure 2a-c. During the plasma discharge, the resulting radicals initially formed short graphitic-like layers that finally aggregated into sphere-like structures. The structure of the N-doped carbon catalysts consists of interconnected nanocarbon balls. From Table 1, certain amount of nitrogen in the aniline precursor was retained within the carbon matrix (3-5 at.\%). Figure $2 \mathrm{~d}-\mathrm{f}$ show the mapping of EDX of metal NPs on N-doped carbon. Based on the SEM and EDX images, the metal NPs are highly dispersed and quite uniformly distributed on $\mathrm{N}$-doped carbon support.

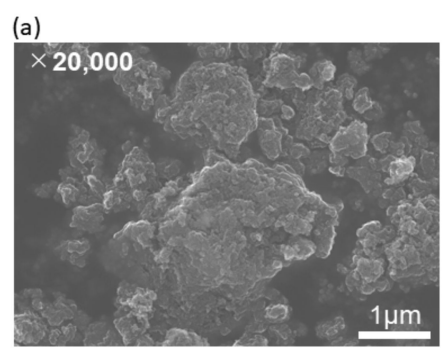

(d)

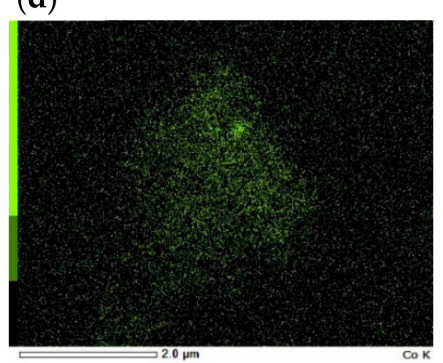

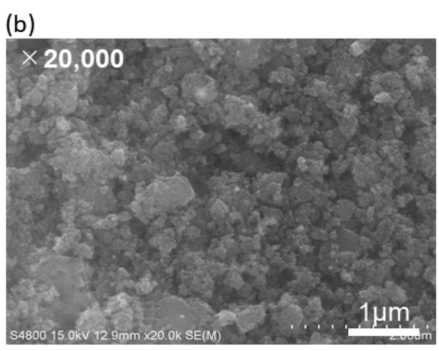

(e)

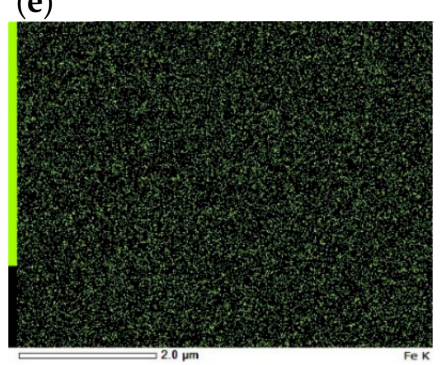

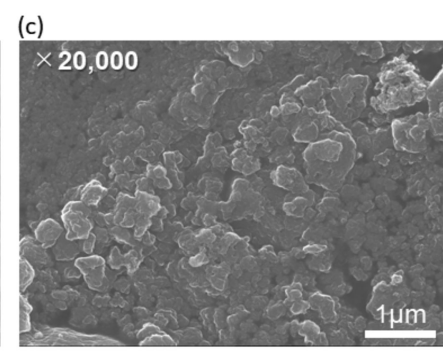

(f)

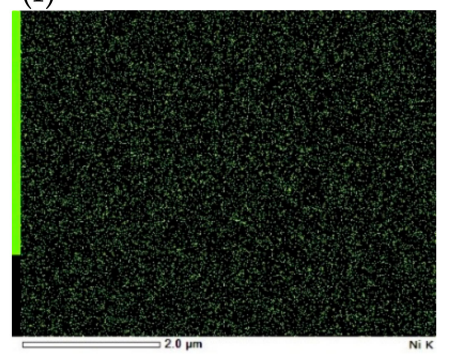

Figure 2. Scanning Electron Microscopy (SEM) images of (a,d) Co-N/C, (b,e) Fe-N/C, and (c,f) Ni-N/C at magnification of $\times 20,000$ and their corresponding EDS images of metal NPs, respectively.

Table 1. Atomic percentages of $\mathrm{C}, \mathrm{N}, \mathrm{H}$ of each metal (Fe, $\mathrm{Co}, \mathrm{Ni})-\mathrm{N} / \mathrm{C}$ from EDS.

\begin{tabular}{cccc}
\hline & Co-N/C & Fe-N/C & Ni-N/C \\
\hline C (at. \%) & $83.4 \%$ & $85.5 \%$ & $79.8 \%$ \\
N (at. \%) & $5.1 \%$ & $5.6 \%$ & $3.2 \%$ \\
H (at. \%) & $2.4 \%$ & $1.51 \%$ & $1.1 \%$ \\
\hline
\end{tabular}

Table 2 summarizes the surface area and the average pore diameter of metal-N-doped carbons as estimated by the BET adsorption-desorption method. The surface area of metal-N-doped carbons is approximately $140 \mathrm{~m}^{2} / \mathrm{g}$ and the average pore diameter is $12-15 \mathrm{~nm}$. Fe-N/C shows the largest surface area $\left(145.3 \mathrm{~m}^{2} / \mathrm{g}\right)$ and average pore diameter $(15.3 \mathrm{~nm})$, followed by Co-N/C $\left(144.8 \mathrm{~m}^{2} / \mathrm{g}\right)$ and $\mathrm{Ni}-\mathrm{N} / \mathrm{C}\left(138.6 \mathrm{~m}^{2} / \mathrm{g}\right)$. The $\mathrm{N}_{2}$ adsorption-desorption isotherm of Fe-N/C (Figure S1a) demonstrates a typical IV-type isotherm. A narrow hysteresis loop at higher relative pressures reveals that the N-doped carbon consists of mostly large size mesopores and interconnecting channels. From Figure $\mathrm{S} 1 \mathrm{~b}$, the Barret-Joyner-Halenda $(\mathrm{BJH})$ adsorption pore size distribution also confirms that the catalysts consist of mesoporous pore structure with 10-20 nm. Figure 3 shows the XRD patterns of the three metal (Fe, Co, Ni)-N-doped carbons. All three samples exhibit a similar pattern, with a broad peak of

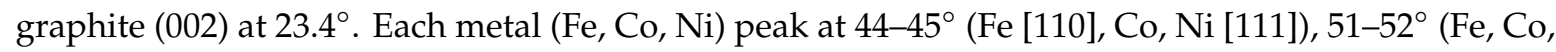
$\mathrm{Ni}[200])$ and $75-76^{\circ}$ (Fe [211], $\mathrm{Co}, \mathrm{Ni}$ [220]) indicates that the metal particles generated by electrode sputtering were successfully doped and present as its pure metal form on the N-doped carbon matrix. 
Table 2. Textural parameters of metal ( $\mathrm{Co}, \mathrm{Fe}, \mathrm{Ni})-\mathrm{N} / \mathrm{C}$ derived from the $\mathrm{N}_{2}$ adsorption-desorption isotherms.

\begin{tabular}{cccc}
\hline & Co-N/C & Fe-N/C & Ni-N/C \\
\hline BET surface area & $144.8 \mathrm{~m}^{2} / \mathrm{g}$ & $145.3 \mathrm{~m}^{2} / \mathrm{g}$ & $138.6 \mathrm{~m}^{2} / \mathrm{g}$ \\
BJH Adsorption pore average width & $12 \mathrm{~nm}$ & $15.3 \mathrm{~nm}$ & $12.8 \mathrm{~nm}$ \\
\hline
\end{tabular}

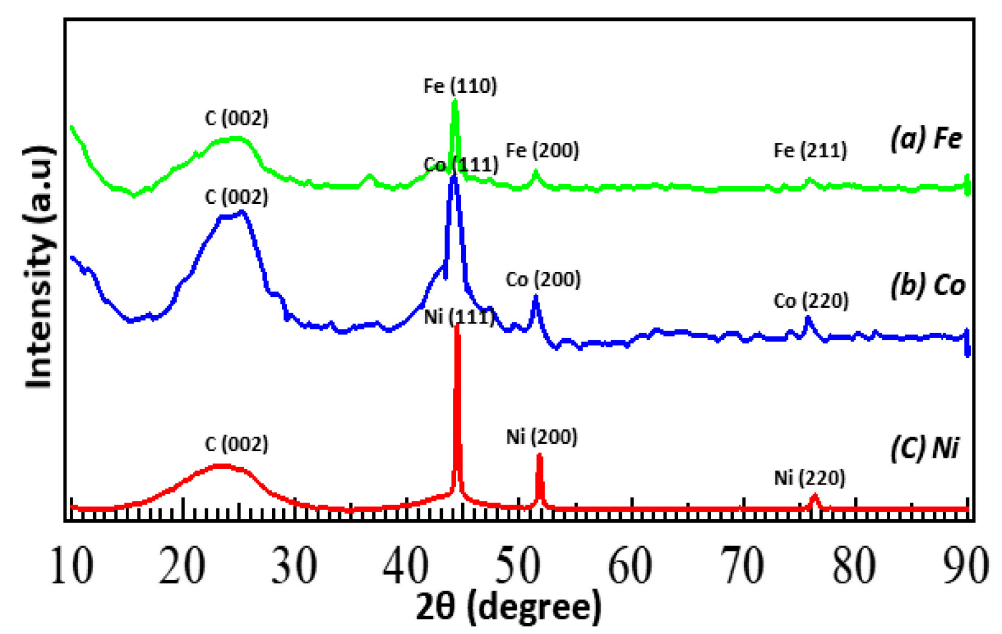

Figure 3. XRD patterns obtained for metal (Fe, $\mathrm{Co}, \mathrm{Ni})-\mathrm{N} / \mathrm{C}$.

\subsection{Chemical Bonding States of Metal (Fe, Co, Ni)-N/C Catalyst}

Surface analyses were performed in order to analyze the chemical bonding type of $\mathrm{N}$-doped carbon. The C1s spectra of each catalyst are shown in Figure 4a-c. All samples showed similar bonding states in the $\mathrm{C} 1 \mathrm{~s}$ spectra. The sp2 graphitic structure and sp3 $\mathrm{C}-\mathrm{C}$ bonding $(\mathrm{C} 1: 284.5 \mathrm{eV}$, C2: $285.6 \mathrm{eV})$ were the most dominant peaks, followed by $\mathrm{C}-\mathrm{N}(\mathrm{C} 3: 286.0 \mathrm{eV}), \mathrm{C}-\mathrm{O}(\mathrm{C} 4: 286.5 \mathrm{eV})$ and $\mathrm{O}-\mathrm{C}=\mathrm{O}(\mathrm{C}-5: 288.7 \mathrm{eV})$ bonding. The presence of $\mathrm{C}-\mathrm{O}$ and $\mathrm{O}-\mathrm{C}=\mathrm{O}$ are commonly due to the oxidation of the carbon surface [45]. Figure $4 \mathrm{~d}-\mathrm{f}$ demonstrate the narrow scan of N1s, which are further deconvoluted into 5 nitrogen-carbon $(\mathrm{N}-\mathrm{C})$ bonding states (N1: Oxide-N, N2: Pyrrolic-N, N3: Graphitic-N, N4: Amino-N, N5: Pyridinic-N). The amino-N (23-31\%) clearly dominates in all metal-N/C catalyst, followed by graphitic-N (19-25\%) and pyridinic-N $(18-24 \%)$. The $\mathrm{N}-\mathrm{C}$ bonding states are similar for all catalysts, which indicates that the structure of the aniline precursor affects the preference of the $\mathrm{N}-\mathrm{C}$ bonding state. This result, therefore, confirms that the $\mathrm{N}-\mathrm{C}$ bonding state of the catalyst synthesized by the solution plasma method is highly affected by the original precursor. Table 3 summarizes the $\mathrm{N}-\mathrm{C}$ bonding types and their corresponding percentages of each catalyst.

Table 3. Bonding states of nitrogen-carbon in metal ( $\mathrm{Co}, \mathrm{Fe}, \mathrm{Ni})$-N-doped catalysts from deconvolution of $\mathrm{N} 1 \mathrm{~s}$ spectra.

\begin{tabular}{ccccc}
\hline \multirow{2}{*}{ Bonding } & \multirow{2}{*}{ Binding Energy } & Co-N/C & Fe-N/C & Ni-N/C \\
\cline { 3 - 5 } & & \multicolumn{2}{c}{ Relative Percentage (\%) } \\
\hline N1(Oxide-N) & $403.3-403.7 \mathrm{eV}$ & 5 & 4.3 & 16.2 \\
N2(Pyrrolic-N) & $401.1-401.5 \mathrm{eV}$ & 20.6 & 16.8 & 16.5 \\
N3(Graphitic-N) & $400.1-400.3 \mathrm{eV}$ & 21.1 & 24.1 & 21.2 \\
N4(Amino-N) & $399.4-399.6 \mathrm{eV}$ & 28.7 & 31 & 26.7 \\
N5(Pyridinic-N) & $398.4-398.6 \mathrm{eV}$ & 24.6 & 23.8 & 19.4 \\
\hline
\end{tabular}



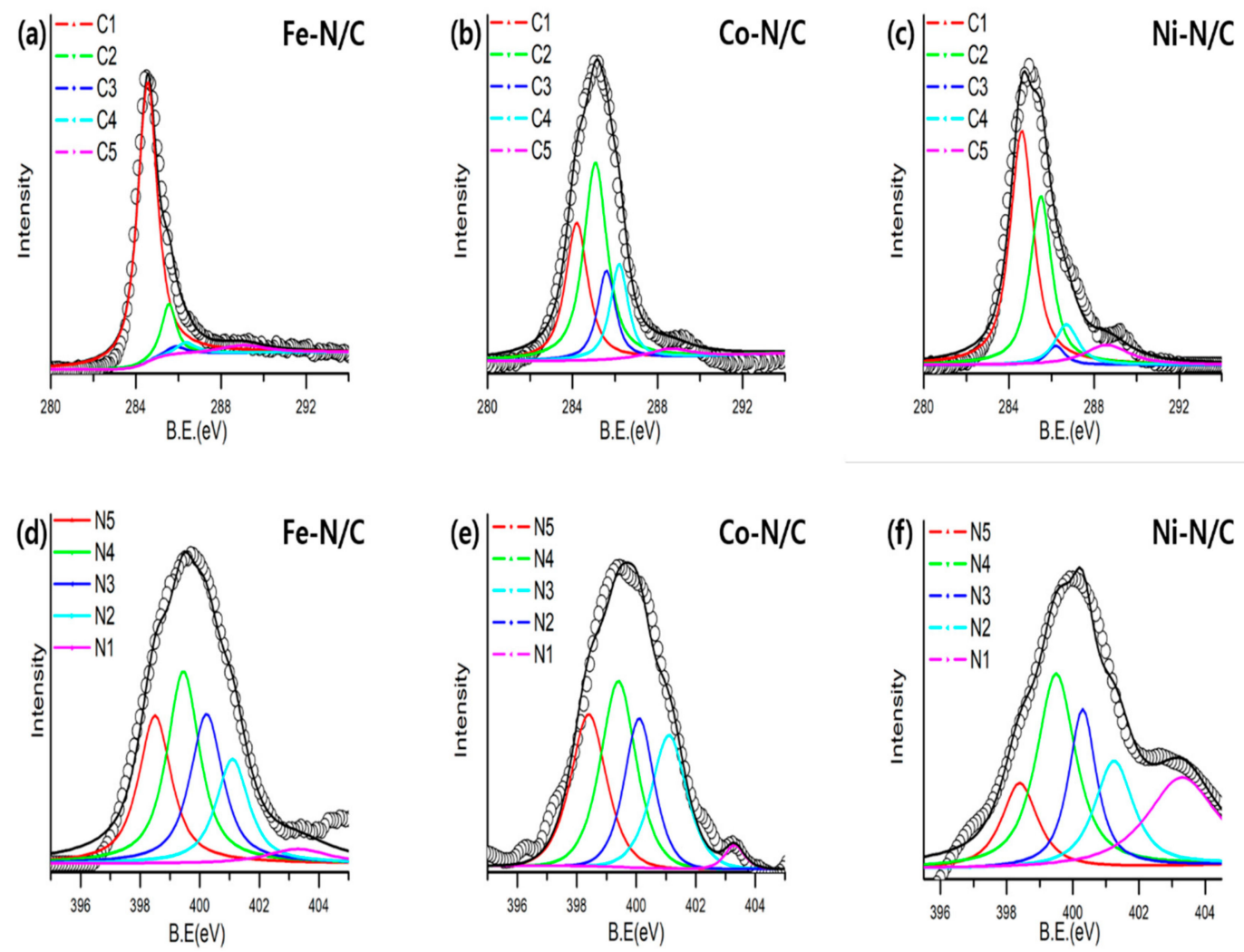

Figure 4. (a-c) High-resolution C 1s XPS spectra with peak deconvolution of metal (Fe, Co, Ni)-N/C, and (d-f) N 1s XPS spectra with peak deconvolution of metal (Fe, Co, Ni)-N/C.

\subsection{Electrochemical Properties of the Metal ( $\mathrm{Fe}, \mathrm{Co}, \mathrm{Ni})$-N/C Catalyst}

Figure 5a-d show CV polarization curves for metal-N/C and $20 \mathrm{wt} . \% \mathrm{Pt} / \mathrm{C}$ up to 3000 cycles at a scan rate of $50 \mathrm{mVs}^{-1}$ in $\mathrm{O}_{2}$-saturated $0.1 \mathrm{M} \mathrm{KOH}$ solution. The ORR onset potential of $\mathrm{Fe}-\mathrm{N} / \mathrm{C}$ and $\mathrm{Co}-\mathrm{N} / \mathrm{C}$ are almost the same (0.93 V vs. RHE), where Ni-N/C exhibits a lower onset potential ( $0.88 \mathrm{~V}$ vs. RHE). Similar to other studies reported on transition metal-doped carbon, the catalytic activities of Fe-N/C and Co-N/C are normally higher than that of Ni-N/C [32]. Our group has already conducted metal-free amino-N-doped carbon with the plasma method and applied aniline as a C-N precursor. From the previous study, selective bonding was achieved with amino-N as the most pronounced bonding (49\%), where its corresponding ORR onset potential was reported as $0.82 \mathrm{~V}$ vs. RHE [37]. Compared to that of the metal-free amino-N/C, current research suggests that metal NPs coordinated with a $\mathrm{N}$-doped carbon matrix provide a synergic effect on advanced ORR performance.

The ORR $E_{1 / 2}$ potential of Fe-N/C and Co-N/C also show similarity ( $0.84 \mathrm{~V}$ vs. RHE (Co-N/C), $0.82 \mathrm{~V}$ vs. RHE (Fe-N/C)), where Ni-N/C exhibits a lower $E_{1 / 2}$ potential ( $0.78 \mathrm{~V}$ vs. RHE). In contrast, Fe-N/C shows the highest $E_{1 / 2}$ current density $\left(5.12 \mathrm{~mA} / \mathrm{cm}^{2}\right)$, followed by Co-N/C $\left(3.36 \mathrm{~mA} / \mathrm{cm}^{2}\right)$, and Ni-N/C $\left(2.26 \mathrm{~mA} / \mathrm{cm}^{2}\right)$. Table 4 summarizes the onset potential and maximum current density at 100 and 3000 cycles, respectively, for each electrocatalyst. Although the current densities of all three as-synthesized catalysts decrease at 3000 cycles, their onset potentials remain relatively stable compared to that of $20 \mathrm{wt} . \% \mathrm{Pt} / \mathrm{C}$. Table 4 summarizes the onset potential and maximum current density at 100 and 3000 cycles, respectively, for each electrocatalyst. Other studies have proposed that metal cations coordinated by graphitic-N and pyridinic-N play an important role in ORR activity [27-30]. Based on our result, we suggest that transition metal doped with selective amino-N bonding also has a positive synergetic effect on ORR activity. 

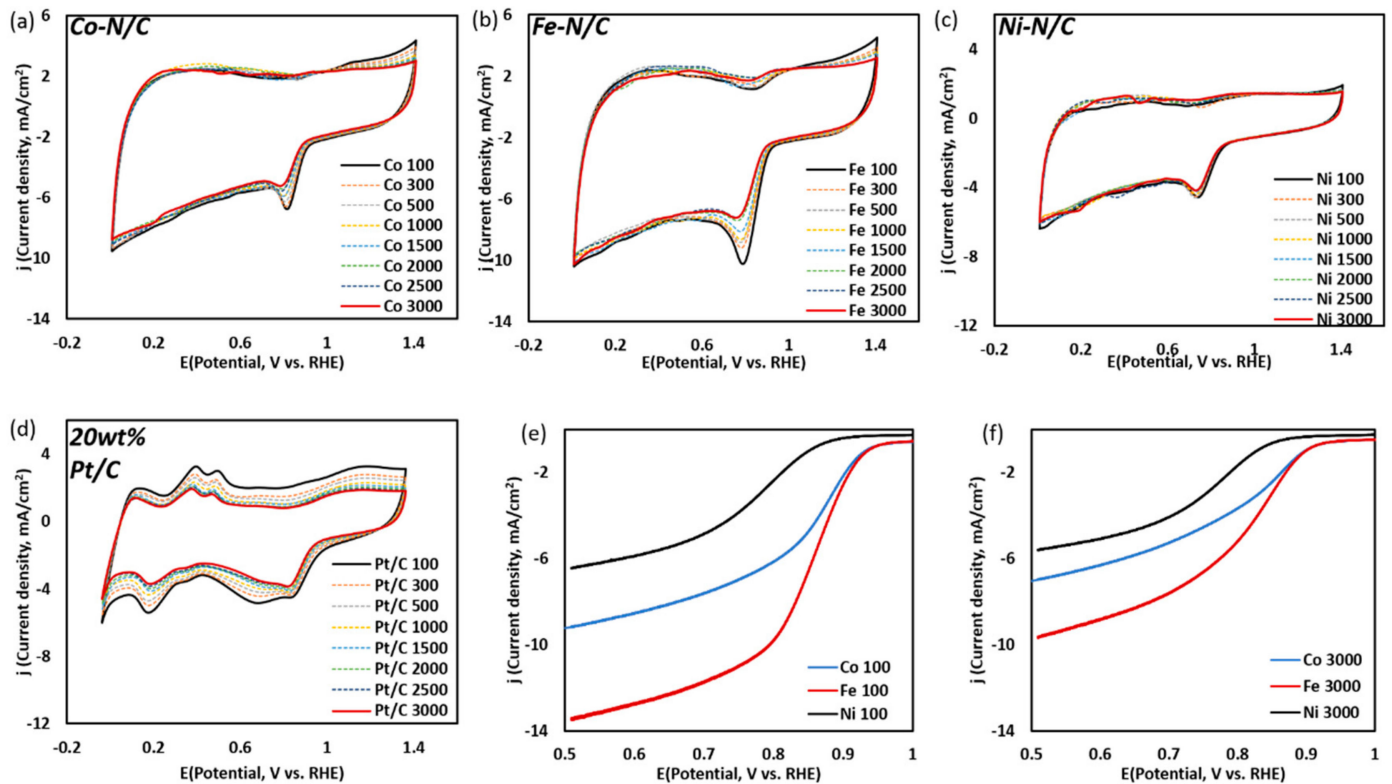

Figure 5. (a-d) CV curves of metal (Co, Fe, Ni)-N/C and $20 \mathrm{wt} . \% \mathrm{Pt} / \mathrm{C}$ from 100 to 3000 cycles at $50 \mathrm{mVs}^{-1}$ in $\mathrm{O}_{2}$ saturated $0.1 \mathrm{M} \mathrm{KOH}$ : (a) Co-N/C, (b) Fe-N/C, (c) Ni-/C and (d) $20 \mathrm{wt} . \% \mathrm{Pt} / \mathrm{C}$, and $\left(\right.$ e,f) LSV curves of metal $(\mathrm{Co}, \mathrm{Fe}, \mathrm{Ni})-\mathrm{N} / \mathrm{C}$ at $10 \mathrm{mVs}^{-1}$ scan rate in $\mathrm{O}_{2}$ saturated $0.1 \mathrm{M} \mathrm{KOH}$ electrolyte: (e) after 100 cycles, and (f) after 3000 cycles.

Table 4. Summary of the electrochemical catalytic activity of metal (Co, Fe, Ni)-N/C and $20 \mathrm{wt} . \% \mathrm{Pt} / \mathrm{C}$.

\begin{tabular}{|c|c|c|c|c|}
\hline & $\mathrm{Co}-\mathrm{N} / \mathrm{C}$ & $\mathrm{Fe}-\mathrm{N} / \mathrm{C}$ & $\mathrm{Ni}-\mathrm{N} / \mathrm{C}$ & 20 wt. $\% \mathrm{Pt} / \mathrm{C}$ \\
\hline $\begin{array}{l}\text { Onset Potential } \\
@ 100 \text { cycles }\end{array}$ & $0.93 \mathrm{~V}$ vs. RHE & $0.93 \mathrm{~V}$ vs. RHE & $0.88 \mathrm{~V}$ vs. RHE & $1.03 \mathrm{~V}$ vs. RHE \\
\hline $\begin{array}{c}\text { Potential } E_{1 / 2} \\
@ 100 \text { cycles }\end{array}$ & $0.84 \mathrm{~V}$ vs. RHE & $0.82 \mathrm{~V}$ vs. RHE & $0.78 \mathrm{~V}$ vs. RHE & $0.94 \mathrm{~V}$ vs. RHE \\
\hline $\begin{array}{l}\text { Current density at } \\
E_{1 / 2} @ 100 \text { cycles }\end{array}$ & $3.36 \mathrm{~mA} / \mathrm{cm}^{2}$ & $5.12 \mathrm{~mA} / \mathrm{cm}^{2}$ & $2.26 \mathrm{~mA} / \mathrm{cm}^{2}$ & $2.22 \mathrm{~mA} / \mathrm{cm}^{2}$ \\
\hline $\begin{array}{l}\text { Onset Potential } \\
@ 3000 \text { cycles }\end{array}$ & $0.90 \mathrm{~V}$ vs. RHE & $0.90 \mathrm{~V}$ vs. RHE & $0.85 \mathrm{~V}$ vs. RHE & $0.94 \mathrm{~V}$ vs. RHE \\
\hline $\begin{array}{l}\text { Potential } E_{1 / 2} \\
@ 3000 \text { cycles }\end{array}$ & $0.83 \mathrm{~V}$ vs. RHE & $0.81 \mathrm{~V}$ vs. RHE & $0.77 \mathrm{~V}$ vs. RHE & $0.91 \mathrm{~V}$ vs. RHE \\
\hline $\begin{array}{l}\text { Current density at } \\
E_{1 / 2} @ 3000 \text { cycles }\end{array}$ & $2.07 \mathrm{~mA} / \mathrm{cm}^{2}$ & $3.62 \mathrm{~mA} / \mathrm{cm}^{2}$ & $2.07 \mathrm{~mA} / \mathrm{cm}^{2}$ & $1.90 \mathrm{~mA} / \mathrm{cm}^{2}$ \\
\hline
\end{tabular}

In Figure $6 \mathrm{a}, \mathrm{b}$, the electron transfer number $(n)$ is derived from the equation $\mathrm{n}=4 \times \frac{i d}{i d+i \mathrm{r} / \mathrm{Nc}^{\prime}}$, where $i_{d}$ is the disk current, $i_{r}$ is the ring current, and $N_{c}$ is the collection efficiency ( 0.42 from the manufacturer). The behavior of the catalysts towards the ORR in alkaline media are as follows [46]:

When the overall reaction is 4-electron:

$$
\mathrm{O}_{2}+\mathrm{H}_{2} \mathrm{O}+4 \mathrm{e}^{-} \rightarrow 4 \mathrm{OH}^{-}
$$

When it is a 2-electron reaction:

$$
\mathrm{O}_{2}+\mathrm{H}_{2} \mathrm{O}+2 \mathrm{e}^{-} \rightarrow \mathrm{HO}_{2}^{-}
$$

followed by

$$
\mathrm{HO}_{2}^{-}+\mathrm{H}_{2} \mathrm{O}+2 \mathrm{e}^{-} \rightarrow 3 \mathrm{OH}^{-}
$$


The calculated electron transfer number $(n)$ at $0.5 \mathrm{~V}$ vs RHE are in the order of $20 \mathrm{wt} . \% \mathrm{Pt} / \mathrm{C}$ (3.97) $>$ Co-N/C (3.81) > Fe-N/C (3.50) > Ni-N/C (2.88). Normally, the ORR takes place mainly through a 2-electron pathway through $\mathrm{HO}_{2}{ }^{-}$formation at the pristine carbon surfaces, whereas it follows a 4-electron pathway in Pt catalysts. As a result, the catalytic system of commercial $20 \mathrm{wt}$. $\% \mathrm{Pt} / \mathrm{C}$ is expected to find a mixed behavior between the two proposed mechanisms, but the electron transfer number $n$ should be very close to 4 [46]. Among all transitional metal-N/C catalysts, Co-N/C shows the highest electron transfer number $n$, as well as a similar behavior to $\mathrm{Pt} / \mathrm{C}$. On the contrary, Fe-N/C and Ni-N/C exhibit a different trend compared to Co-N/C and $\mathrm{Pt} / \mathrm{C}$. The behavior of these two catalysts is almost the same compared to other $\mathrm{N}$-doped carbon catalysts, of which their reported $n$ values were 2.5-3.7 [47]. As the major C-N bondings of all transitional metal-N/C catalysts have no major differences, it is easy to observe that Co NP provides higher selectivity of the 4-electron pathway.
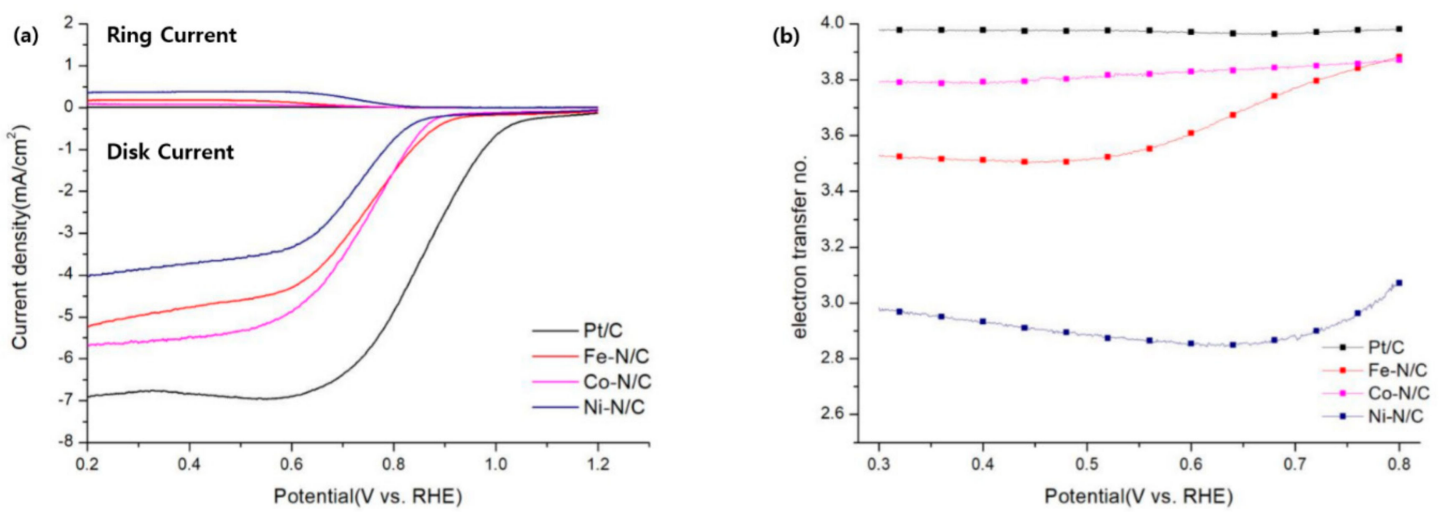

Figure 6. (a) RRDE analysis @1600 rpm of (Co, Fe, Ni)-N/C and 20 wt. $\% \mathrm{Pt} / \mathrm{C}$ at $10 \mathrm{mVs}^{-1}$ in $\mathrm{O}_{2}$ saturated $0.1 \mathrm{M} \mathrm{KOH}$ solution at a scan rate of $10 \mathrm{mV} \mathrm{s}^{-1}$ and a rotation speed of $1600 \mathrm{rpm}$, and (b) the correlated electron number of (Co, Fe, Ni)-N/C and $20 \mathrm{wt}$ \% $\% \mathrm{Pt} / \mathrm{C}$ between $0.3 \mathrm{~V}$ to $0.8 \mathrm{~V}$ vs. RHE.

\section{Conclusions}

Transitional metal/amino-N-doped carbon was synthesized via a plasma process using aniline and a transition metals (Fe, Co, Ni) electrode as starting precursors. Both SEM and XRD analyses confirmed that the metal NPs were successfully doped on the N-doped carbon support. Surface analysis revealed that amino- $\mathrm{N}$ was the dominant bonding state in all electrocatalysts, which suggests that the starting precursor played a significant role in the chemical bonding state. Compared to metal-free N-doped carbon, metal NPs on N-doped carbon have a synergic effect on advanced ORR performance. In the electrochemical testing, Co-N/C carbon showed the best $\boldsymbol{E}_{1 / 2}$ potential (0.84 V vs. RHE) and Fe-N/C exhibited the highest $E_{1 / 2}$ current density $\left(5.12 \mathrm{~mA} / \mathrm{cm}^{2}\right)$. Within all types of TM-NPs-N/C catalyst, Co-N/C showed the highest onset ORR potential and high selectivity in the $4 \mathrm{e}^{-}$reaction pathway. Although its catalytic performance was still slightly lower than that of commercial $20 \mathrm{wt}$.\% Pt catalyst, its low cost, and relatively high catalytic performance hold promise as alternative ORR electrocatalysts in the practical metal-air battery.

Supplementary Materials: The following are available online at http://www.mdpi.com/2079-4991/9/5/742/s1. BET adsorption -desorption of Fe-N/C, (a) Isotherm linear adsorption-desorption plot of $\mathrm{Fe}-\mathrm{N} / \mathrm{C}$, (b) BJH adsorption pore size distribution.

Author Contributions: S.K. (Seonghee Kim) analyzed all the electrochemical data and wrote the manuscript. S.K. (Shuhei Kato) and T.I. have focused on material analyses including SEM, XRD, and XPS. O.L.L. and J.K. helped in the data analysis of electrochemistry, discussion of the results and revised the manuscript. All authors discussed the results and contributed to manuscript preparation.

Funding: This work was supported by a 2-Year Research Grant of Pusan National University.

Conflicts of Interest: The authors declare no conflict of interest. 


\section{References}

1. Zhang, Z.; Zhang, S.S. Rechargeable Batteries: Materials, Technologies and New Trends; Springer: Heidelberg, Germany, 2015; pp. 511-580.

2. Li, Y.; Lu, L. Metal-Air Batteries: Will They Be the Future Electrochemical Energy Storage Device of Choice? ACS Energy Lett. 2017, 2, 1370-1377. [CrossRef]

3. Gu, P.; Zheng, M.; Zhao, Q.; Xiao, X.; Xue, H.; Pang, H. Rechargeable Zinc-air batteries: A promising way to green energy. J. Mater. Chem. A 2017, 5, 7651-7666. [CrossRef]

4. Zhang, X.; Wang, X.G.; Xie, Z.; Zhou, Z. Recent progress in rechargeable alkali metal-air batteries. Green Energy Environ. 2016, 1, 4-17. [CrossRef]

5. Nie, Y.; Li, L.; Wei, Z. Recent Advancements in Pt and Pt-free Catalysts for Oxygen Reduction Reaction. Chem. Soc. Rev. 2015, 44, 2168-2201. [CrossRef] [PubMed]

6. Park, J.; Park, M.; Nam, G.; Lee, J.S.; Cho, J. All-Solid-State Cable-Type Flexible Zinc-Air Battery. Adv. Mater. 2015, 78, 1396-1401. [CrossRef]

7. Wang, X.; Orikasa, Y.; Uchimoto, Y. Platinum-based Electrocatalysts for the Oxygen-Reduction Reaction: Determining the Role of Pure Electronic Charge Transfer in Electrocatalysis. ACS Catal. 2016, 6, 4195-4198. [CrossRef]

8. Shui, J.; Wang, M.; Du, F.; Dai, L. N-doped carbon nanomaterials are durable catalysts for oxygen reduction reaction in acidic fuel cells. Sci. Adv. 2015, 1, e1400129. [CrossRef] [PubMed]

9. Gong, K.; Du, F.; Xia, Z.; Durstock, M.; Dai, L. Nitrogen-Doped Carbon Nanotube Arrays with High Electrocatalytic Activity for Oxygen Reduction. Science 2009, 323, 760-764. [CrossRef] [PubMed]

10. Geng, D.; Chen, Y.; Chen, Y.; Li, Y.; Li, R.; Sun, X.; Ye, S.; Knights, S. High oxygen-reduction activity and durability of nitrogen-doped graphene. Energy Environ. Sci. 2011, 4, 760-764. [CrossRef]

11. Zhao, S.; Wang, D.W.; Amal, R.; Dai, L. Carbon-Based Metal-Free Catalysts for Key Reactions Involved in Energy Conversion and Storage. Adv. Mater. 2019, 31, 1801526. [CrossRef] [PubMed]

12. Zhang, J.; Dai, L. Heteroatom-Doped Graphitic carbon Catalysts for Efficient Electrocatalysis of Oxygen Reduction Reaction. ACS Catal. 2015, 5, 7244-7253. [CrossRef]

13. Liu, D.; Dai, L.; Lin, X.; Chen, J.F.; Zhang, J.; Feng, X.; Mullen, K.; Zhu, X.; Dai, S. Chemical Approaches to Carbon-Based Metal-Free Catalysts. Adv. Mater. 2019, 31, 1804863. [CrossRef] [PubMed]

14. Qu, L.; Liu, Y.; Baek, J.B.; Dal, L. Nitrogen-Doped Graphene as Efficient Metal-Free Electrocatalyst for Oxygen Reduction in Fuel cells. ACS Nano 2010, 4, 1321-1326. [CrossRef] [PubMed]

15. Xing, T.; Zheng, Y.; Li, L.H.; Cowie, B.C.C.; Gunzelmann, D.; Qiao, S.Z.; Huang, S.; Chen, Y. Observation of Active Sites for Oxygen Reduction on Nitrogen-Doped Multilayer Graphene. ACS Nano 2014, 8, 6856-6862. [CrossRef]

16. Tuci, G.; Zafferoni, C.; Rossin, A.; Milella, A.; Luconi, L.; Innocenti, M.; Phuoc, L.T.; Duong-Viet, C.; Pham-Huu, C.; Giambastiani, G. Chemically Functionalized Carbon Nanotubes with Pyridine Groups as easily Tunable N-Decorated nanomaterials for the Oxygen Reduction Reaction in Alkaline Medium. Chem. Mater. 2014, 26, 3460-3470. [CrossRef]

17. Guo, D.; Shibuya, R.; Akiba, C.; Saji, S.; Kondo, T.; Nakamura, J. Active sites of nitrogen-doped carbon materials for oxygen reduction reaction clarified using model catalysts. Science 2016, 354, 361-365. [CrossRef]

18. Sun, M.; Wu, X.; Deng, X.; Zhang, W.; Xie, Z.; Huang, Q.; Huang, B. Synthesis of pyridinic-N doped carbon nanofibers and its electro-catalytic activity for oxygen reduction reaction. Mater. Lett. 2018, 220, 313-316. [CrossRef]

19. Yan, P.; Liu, J.; Yuan, S.; Liu, Y.; Cen, W.; Chen, Y. The promotion effects of graphitic and pyridinic N combinational doping on graphene for ORR. Appl. Surf. Sci. 2018, 445, 398-403. [CrossRef]

20. Wu, G.; Santandreu, A.; Kellogg, W.; Gupta, S.; Ogoke, O.; Zhang, H.; Wang, H.; Dai, L. Carbon nanocomposite catalysts for oxygen reduction and evolution reactions: From nitrogen doping to transition-metal addition. Nano Energy 2016, 29, 83-110. [CrossRef]

21. Lenarda, A.; Bevilacqua, M.; Tavagnacco, C.; Nasi, L.; Criado, A.; Vizza, F.; Melchionna, M.; Prato, M.; Fornasiero, P. Selective $\mathrm{H}_{2} \mathrm{O}_{2}$ electrocatalytic generation by Cobalt@N-doped graphitic carbon core-shell nanohybrids. ChemSusChem 2019, 12, 1664-1672. [CrossRef] 
22. Iglesias, D.; Giuliani, A.; Melchionna, M.; Marchesan, S.; Criado, A.; Nasi, L.; Bevillacqua, M.; Tavagnacco, C.; Vizza, F.; Prato, M.; et al. N-Doped Graphitized Carbon Nanohorns as a Forefornt Electrocatalyst in Highly Selective $\mathrm{O}_{2}$ Reduction to $\mathrm{H}_{2} \mathrm{O}_{2}$. Chem 2018, 4, 106-123. [CrossRef]

23. Wu, G.; More, K.L.; Johnston, C.M.; Zelenay, P. High-Performance Electrocatalysts for Oxygen Reduction Derived from Polyaniline, Iron, and Cobalt. Science 2011, 332, 443-447. [CrossRef]

24. Oh, H.S.; Kim, H.S. The role of transition metals in non-precious nitrogen-modified carbon-based electrocatalysts for oxygen reduction reaction. J. Power Source 2012, 212, 220-225. [CrossRef]

25. Yasuda, S.; Uchibori, Y.; Wakeshima, M.; Hinatsu, Y.; Ogawa, H.; Yano, M.; Asaoka, H. Enhancement of Fe-N-C carbon catalyst activity for the oxygen reduction reaction: Effective increment of active sites by a short and repeated heating process. RSC Adv. 2018, 8, 37600-37605. [CrossRef]

26. Shi, Z.; Liu, H.; Lee, K.; Dy, E.; Chlistunoff, J.; Blair, M.; Zelenay, P.; Zhang, J.; Liu, Z. Theoretical Study of Possible Active Structures in Cobalt-Polypyrrole catalysts for Oxygen Reduction reaction. J. Phys. Chem. C 2011, 115, 16672-16680. [CrossRef]

27. Kramm, U.I.; Herrmann-Geppert, I.; Behrends, J.; Lips, K.; Fiechter, S.; Bogdanoff, P. On an Easy Way to Prepare Metal-Nitrogen Doped carbon with Exclusive Presence of MeN4-type Sites Active for the ORR. J. Am. Chem. Soc. 2016, 138, 635-640. [CrossRef] [PubMed]

28. Qian, Y.; Liu, Z.; Zhang, H.; Wu, P.; Cai, C. Active Site Structures in Nitrogen-Doped Carbon-Supported Cobalt Catalysts for the Oxygen Reduction Reaction. ACS Appl. Mater. Interfaces 2016, 8, 32875-32886. [CrossRef]

29. Peng, H.; Mo, Z.; Liao, S.; Liang, H.; Yang, L.; Luo, F.; Song, H.; Zhong, Y.; Zhang, B. High-Performance Fe- and N- Doped Carbon Catalyst with Graphene Structure for Oxygen Reduction. Sci. Rep. 2013, 3, 1765. [CrossRef]

30. Du, J.; Cheng, F.; Wang, S.; Zhang, T.; Chen, J. M(Salen)-derived Nitrogen-doped M/C(M = Fe, Co, Ni) Porous Nanocomposites for Electrocatalytic Oxygen Reduction. Sci. Rep. 2014, 4, 4386. [CrossRef]

31. Peng, H.; Liu, F.; Liu, X.; Liao, S.; Yu, C.; Tian, X.; Nan, H.; Luo, F.; Song, H.; Fu, Z.; et al. Effect of Transition Metals on the Structure and Performance of the Doped Carbon catalysts Derived From Polyaniline and Melamine for ORR Application. ACS Catal. 2014, 4, 3797-3805. [CrossRef]

32. Tang, H.; Chen, W.; Wang, J.; Dugger, T.; Cruz, L.; Kisailus, D. Electrocatalytic N-Doped Graphitic Nanofiber-Metal/Metal Oxide Nanoparticle Composites. Small 2018, 14, 1703459. [CrossRef]

33. Zeng, D.; Huang, J.; Lin, Z.; Yu, X.; Zhan, Y.; Xie, F.; Zhang, W.; Chen, J.; Meng, H. Non-noble metal catalyst on carbon ribbon for fuel cell cathode. J. Solid State Electrochem. 2018, 22, 761-771. [CrossRef]

34. Zhang, C.; Hao, R.; Liao, H.; Hou, Y. Synthesis of amino-functionalized graphene as metal-free catalyst and exploration of the roles of various nitrogen states in the oxygen reduction reaction. Nano Energy 2013, 2, 88-97. [CrossRef]

35. Jiang, Z.; Jiang, Z.; Tian, X.; Chen, W. Amine-functionalized holey graphene as a highly active metal-free catalyst for the oxygen reduction reaction. J. Mater. Chem. A 2014, 2, 441-450. [CrossRef]

36. Li, O.L.; Chiba, S.; Wada, Y.; Panomsuwan, G.; Ishizaki, T. Synthesis of graphitiC-N and amino-N in nitrogen-doped carbon via a solution plasma process and exploration of their synergic effect for advanced oxygen reduction reaction. J. Mater. Chem. A 2017, 5, 2073-2082. [CrossRef]

37. Kim, D.W.; Li, O.L.; Pootawang, P.; Saito, N. Solution plasma synthesis process of tungsten carbide on $\mathrm{N}$-doped carbon nanocomposite with enhanced catalytic ORR activity and durability. RSC Adv. 2014, 4, 16813-16819. [CrossRef]

38. Panomsuwan, G.; Saito, N.; Ishizaki, T. Nitrogen-doped carbon nanoparticles derived from acrylonitrile plasma for electrochemical oxygen reduction. Phys. Chem. Chem. Phys. 2015, 17, 6227-6232. [CrossRef] [PubMed]

39. Panomsuwan, G.; Ciba, S.; Kaneko, Y.; Saito, N.; Ishizaki, T. In situ solution plasma synthesis of nitrogen-doped carbon nanoparticles as metal-free electrocatalysts for the oxygen reduction reaction. J. Mater. Chem. A 2014, 2, 18677-18686. [CrossRef]

40. Panomsuwan, G.; Saito, N.; Ishizaki, T. Simple one-step synthesis of fluorine-doped carbon nanoparticles as potential alternative metal-free electrocatalysts for oxygen reduction reaction. J. Mater. Chem. A 2015, 3, 9972-9981. [CrossRef]

41. Panomsuwan, G.; Saito, N.; Ishizaki, T. Electrocatalytic oxygen reduction activity of boron-doped carbon nanoparticles synthesized via solution plasma process. Electrochem. Commun. 2015, 59, 81-85. [CrossRef] 
42. Chae, S.; Panomsuwan, G.; Bratescu, M.A.; Teshima, K.; Saito, N. p-Type Doping of Graphene with Cationic Nitrogen. ACS Appl. Nano Mater. 2019, 2, 1350-1355. [CrossRef]

43. Horiguchi, G.; Chikaoka, Y.; Shiroishi, H.; Kosaka, S.; Sairo, M.; Kameta, N.; Matsuda, N. Synthesis of Pt nanoparticles as catalysts of oxygen reduction with microbubble-assisted low-voltage and low-frequency solution plasma processing. J. Power Sources 2018, 382, 69-76. [CrossRef]

44. Kim, H.M.; Saito, N.; Kim, D.W. Solution plasma-Assisted Green Synthesis of $\mathrm{MnO}_{2}$ Adsorbent and Removal of cationic Pollutant. J. Chem. 2019, 2019, 7494292. [CrossRef]

45. Rocha, I.M.; Soares, O.S.G.P.; Figueiredo, J.L.; Freire, C.; Pereira, M.F.R. Bifunctionality of the pyrone functional group in oxidized carbon naotubes towards oxygen reduction reaction. Catal. Sci. Technol. 2017, 7, 1868-1879. [CrossRef]

46. Moline-Garcia, M.; Ress, N.V. Effect of catalyst carbon supports on the oxygen reduction reaction in alkaline media: A comparative study. RSC Adv. 2016, 6, 94669-94681. [CrossRef]

47. Zhou, R.; Zheng, Y.; Jaroniec, M.; Qiao, S. Determination of the electron transfer number for the oxygen reduction reaction: From theory to experiment. ACS Catal. 2016, 6, 4720-4728. [CrossRef]

(C) 2019 by the authors. Licensee MDPI, Basel, Switzerland. This article is an open access article distributed under the terms and conditions of the Creative Commons Attribution (CC BY) license (http://creativecommons.org/licenses/by/4.0/). 